\title{
Phase Decomposition in a High-Manganese Steel
}

\author{
M. WiTKOWSKA* \\ AGH-University of Science and Technology, Faculty of Metals Engineering and Industrial Computer Science, \\ Cracow, Poland
}

\begin{abstract}
The present work deals with the texture and microstructure development in high-manganese steel X85MnAl299. It was cold rolled to $50 \%$ reduction and then aged at $550{ }^{\circ} \mathrm{C}$ for various times. The investigations included measurements of texture, X-ray phase analysis and microstructure observations. The results indicate that, when ageing takes place, precipitation of $\kappa^{\prime}$ carbide in an austenitic matrix and carbide $\kappa$ at grain boundaries occur. The existence of satellites suggests that $(\mathrm{Fe}, \mathrm{Mn})_{3} \mathrm{AlC}$ carbides were formed within the austenite matrix by spinodal decomposition.
\end{abstract}

DOI: 10.12693/APhysPolA.130.950

PACS/topics: 81.40.Cd, 81.40.Ef, 81.40.- -

\section{Introduction}

The automotive industry constitutes one of the most dynamically developing branches of the global economy. The research being conducted fulfils requirements relevant to the reduction in the mass of a vehicle, which exerts a direct influence upon the reduction in fuel consumption and damage to the environment inflicted upon it by the emitted exhaust fumes. In recent years, intensive research has been conducted into high-manganese steels having various chemical compositions ( $\mathrm{Mn}, \mathrm{Al}, \mathrm{C}$, and $\mathrm{Si}$ ). An important feature of high-manganese steels is a substantial reserve of plasticity, and that means the ability to absorb energy in the course of a collision, which improves safety of passengers [1-9].

A distinctive feature of these steels is high strength and simultaneously very good plasticity. The advantageous properties of the high-manganese steels can be obtained by a combination of mechanisms of plastic deformation. Transformation induced plasticity (TRIP), twinning induced plasticity (TWIP) and plasticity brought about by the formation of shear bands in austenite (SIP) effects are observed in those kind of steels. The microstructure of the TRIPLEX steels is an austenitic matrix with a small quantity of ferrite (5-15\% of the volume) and $\kappa^{\prime}$ nanocarbides $(\mathrm{Fe}, \mathrm{Mn})_{3} \mathrm{AlC}(\approx 10 \%$ of the volume). In order to obtain a steel with high mechanical properties, including appropriate plasticity, these steels are subjected to ageing within the following range of temperatures: 500 $750^{\circ} \mathrm{C}$. Consequently, a fine modulated structure, which is formed as the result of the spinodal decomposition of austenite, is obtained. As ageing time is extended, carbides are precipitated coherently in the austenitic matrix $\left(\kappa^{\prime}\right)$, as well as heterogeneously on boundaries as coarse particles $(\kappa)$. As ageing time is increased, the following reactions may occur on the boundaries of crystallites $\gamma / \gamma: \gamma \rightarrow \alpha+\kappa, \gamma \rightarrow \alpha+\beta$-Mn, $\gamma \rightarrow \kappa+\beta-\mathrm{Mn}$, $\gamma \rightarrow \alpha+\kappa+\beta$-Mn or $\gamma \rightarrow \gamma_{0}+\kappa$. Microstructure and

\footnotetext{
*corresponding author; e-mail: witkowsk@agh.edu.pl
}

texture of high-manganese steels after annealing result from precipitation of carbides phase, which depend on conditions of annealing treatment [2-4, 6 and 8].

The objective of this research was to analyse changes in the texture and microstructure occurring in the highmanganese X85MnAl29-9 steel after ageing.

\section{Material and methods}

A high-manganese steel, $29 \% \mathrm{Mn}, 9.5 \% \mathrm{Al}$ and $0.85 \% \mathrm{C}$ (percentage by mass), was melted in a vacuum induction melting furnace and cast. After annealing at $1150^{\circ} \mathrm{C}$ for $7 \mathrm{~h}$ in an argon atmosphere, the cast ingot was hot-rolled at $1250{ }^{\circ} \mathrm{C}$, and then $50 \%$ cold-rolled. Subsequently the material was aged at $5500^{\circ} \mathrm{C}$ for various times.

Diffraction examinations were performed on a Siemens D500 diffractometer with copper anode $\left(\lambda_{K_{\alpha}}=\right.$ $0.154 \mathrm{~nm}$ ) monochromatic radiation. Textures were studied using the diffractometric Schultz reflection method on a Bruker D8 Advance diffractometer equipped with the Euler circle and a lamp equipped with a cobalt anode $\left(\lambda_{K_{\alpha}}=0.179 \mathrm{~nm}\right)$. Incomplete pole figures $\{111\}$, $\{200\},\{220\}$, and $\{311\}$ for austenite, upon the basis of which the orientation distribution function (ODF) was calculated, were recorded.

The observations of microstructure were on a Leica DMLM optical microscope and also on a FEI VERSA 3D scanning electron microscope and a JEM 200CX transmission electron microscope.

\section{Results}

The largest changes on the diffractograms were observed for near the $(200) \gamma$ peak. For this very reason, in Fig. 1, the fragments of diffractograms encompassing the relevant range $2 \theta=47-53^{\circ}$ are presented. On the diffraction image of the sample after $50 \%$ deformation there is a single $(200) \gamma$ peak (Fig. 1). After annealing, on the diffractograms there are additional peaks originating from the phases: $\kappa^{\prime}$ and $\kappa$, next to the $(200) \gamma$ one. The intensity of the $(200) \kappa$ peak increases with annealing time from 10 to $100 \mathrm{~h}$. In addition, there is an observable shift of the maximum of a (200) $\gamma$ peak in the direction of 
lower angles $2 \theta$. In Table I, the calculated lattice parameters for austenite and $\kappa^{\prime}$ carbide are included. Initially, as the ageing time increases up to $10 \mathrm{~h}$, increase in the lattice parameter of austenite is observed, whereas, after longer ageing times of 24 and $100 \mathrm{~h}$, the lattice parameter decreases. The new phase $\kappa^{\prime}$ has the ordered fcc structure, and the lattice parameter is $a=0.3728 \mathrm{~nm}$ after $24 \mathrm{~h}$, and $a=0.3724 \mathrm{~nm}$ after $100 \mathrm{~h}$ of ageing. As the duration of ageing is extended, the lattice parameter of $\kappa^{\prime}$ carbide is decreased.

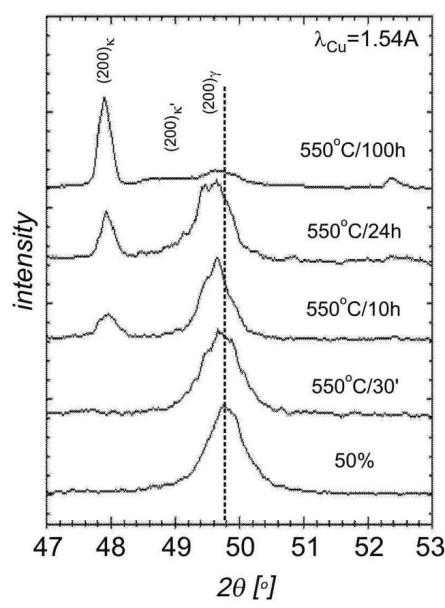

Fig. 1. X-ray diffraction profiles around the (200) $\gamma$ Bragg reflection after rolling deformation and ageing at $550{ }^{\circ} \mathrm{C}$ for various times.

TABLE I

Experimental data obtained from the X-ray diffraction profiles of X85MnAl29-9 steel after 50\% cold rolling and ageing at $550{ }^{\circ} \mathrm{C}$ for various times.

\begin{tabular}{c|c|c|c|c|c|c}
\hline \hline Material & Phase & $50 \%$ & $30^{\prime}$ & $10 \mathrm{~h}$ & $24 \mathrm{~h}$ & $100 \mathrm{~h}$ \\
\hline \multirow{2}{*}{$\begin{array}{c}\text { lattice } \\
\text { parameter [nm] }\end{array}$} & $\gamma$ & 0.3669 & 0.3676 & 0.3680 & 0.3677 & 0.3670 \\
\cline { 2 - 7 } & $\kappa$ & - & - & - & 0.3728 & 0.3724 \\
\hline $\begin{array}{c}\text { margin } \\
\text { of error }\end{array}$ & $\gamma$ & 0.0084 & 0.0096 & 0.0068 & 0.0144 & 0.0180 \\
\cline { 2 - 7 } $\begin{array}{c}\text { relative } \\
\text { error [\%] }\end{array}$ & $\gamma$ & - & - & - & 0.0377 & 0.0620 \\
\cline { 2 - 7 } & $\kappa^{\prime}$ & - & - & - & 1.01 & 1.68 \\
\hline misfit $\delta_{\kappa^{\prime}-\gamma}$ & & - & - & - & 0.0208 & 0.0195 \\
\hline elastic misfit $\delta_{s}$ & & - & - & - & 0.0209 & 0.0144
\end{tabular}

The misfit $\delta_{\kappa^{\prime}-\gamma}$ was calculated using Eq. (1) [7]:

$$
\delta_{\kappa^{\prime}-\gamma}=2\left|\frac{a_{\kappa^{\prime}}-a_{\gamma_{0}}}{a_{\kappa^{\prime}}+a \gamma_{0}}\right|
$$

and the elastic misfit $\delta_{s}$ between $\gamma_{0}$ and $\kappa^{\prime}$ applying Eq. (2):

$$
\delta_{s}=\left(a_{\kappa^{\prime}}-a_{\gamma_{0}}\right) / a_{\gamma_{0}} .
$$

The results are presented in Table I. As the duration of ageing is extended, the misfit $\delta_{\kappa^{\prime}-\gamma}$ and elastic misfit $\delta_{s}$ decrease.

The analysis of the textures was conducted from the point of view of the influence exerted by the process of precipitation occurring in the course of ageing upon

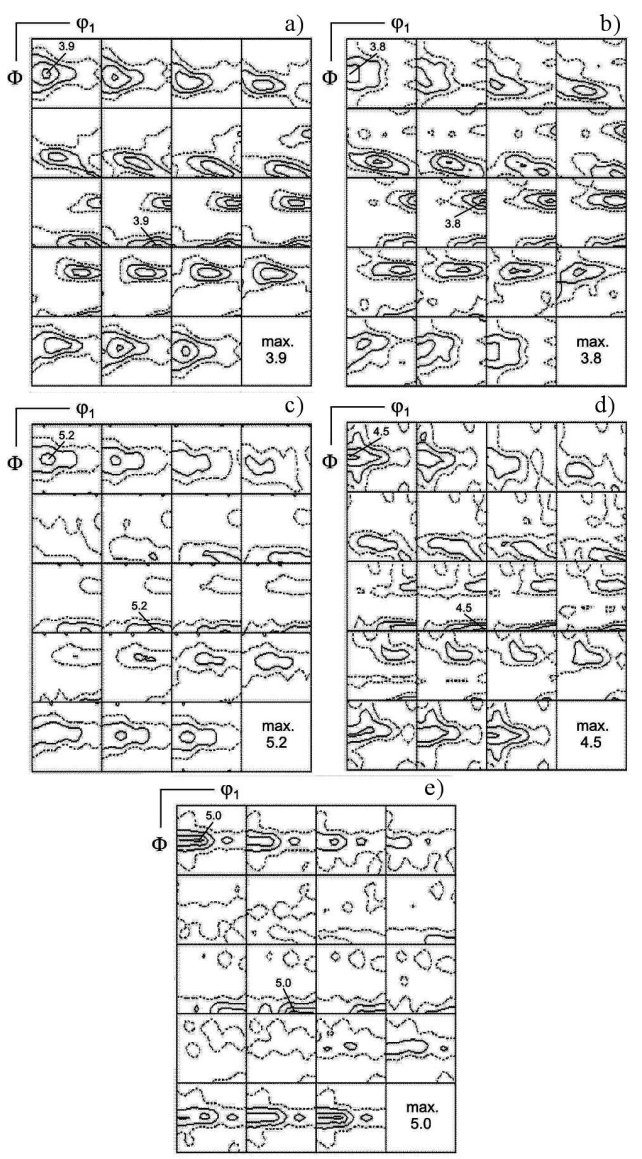

Fig. 2. Orientation distribution functions in sections $\varphi_{2}=$ const for $\gamma$-phase after $50 \%$ cold rolling (a) and

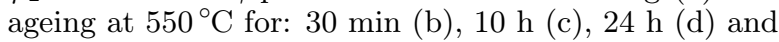
$100 \mathrm{~h}(\mathrm{e})$.

changes to the intensity of the main components of the texture of austenite. For the purpose of the analysis of a high-manganese steel, the orientation distribution function (ODF), presented in Fig. 2, was applied. In the texture of an austenite sample after the $50 \%$ deformation (Fig. 2a), the fibre $\alpha=\langle 110\rangle \| \mathrm{ND}$ (normal direction) was observed. The strongest component of the texture is the orientation $\{110\}\langle 115\rangle$. In addition to that, there occurs a comparatively strong Goss orientation $\{110\}\langle 001\rangle$ and the alloy type orientation $\{110\}\langle 112\rangle$, which is included in $\alpha$ fibre as well. The texture of austenite may be described by heterogeneous fibre $\tau=\langle 110\rangle \| \mathrm{TD}$ (trasnsverse direction) and the fibre $\eta=\langle 001\rangle \| \mathrm{RD}$ (rolling direction).

After annealing for $30 \mathrm{~min}$ (Fig. 2b), no significant changes to the texture of austenite were observed. Simultaneously with extension in the duration of ageing, there occurs an increase in the intensity of the main components being limited by the fibre $\alpha$, which was elongated. In the texture of the austenite sample, after annealing for 10 and $100 \mathrm{~h},\{110\}\langle 113\rangle$ is the strongest component, and after $24 \mathrm{~h}$ it is the Goss orientation $\{110\}\langle 001\rangle$ (Fig. 2c-e). The $\{110\}\langle 112\rangle$ orientation was strengthened in samples after annealing. 
Upon the basis of the X-ray examinations, it was ascertained that in the course of ageing at $550{ }^{\circ} \mathrm{C}$ precipitation of carbide phases $\kappa^{\prime}$ and $\kappa$ occurs. The appearance of a lateral peak (asymmetry) next to the principal one of $200 \gamma$ on diffractograms indicates the presence of $\kappa^{\prime}$ carbide $(\mathrm{Fe}, \mathrm{Mn})_{3} \mathrm{AlC}$ formed as a result of spinodal decomposition.

A significant influence upon the development of texture of annealed austenite are the processes of precipitation. The analysis indicates that the texture of austenite is described by orientations from the strong and limited fibre $\alpha$. Simultaneously with extension in the duration of ageing, the intensity of the Goss orientation increases as well $\{110\}\langle 001\rangle$ and a strong orientation of the alloy type occurs $\{110\}\langle 112\rangle$.

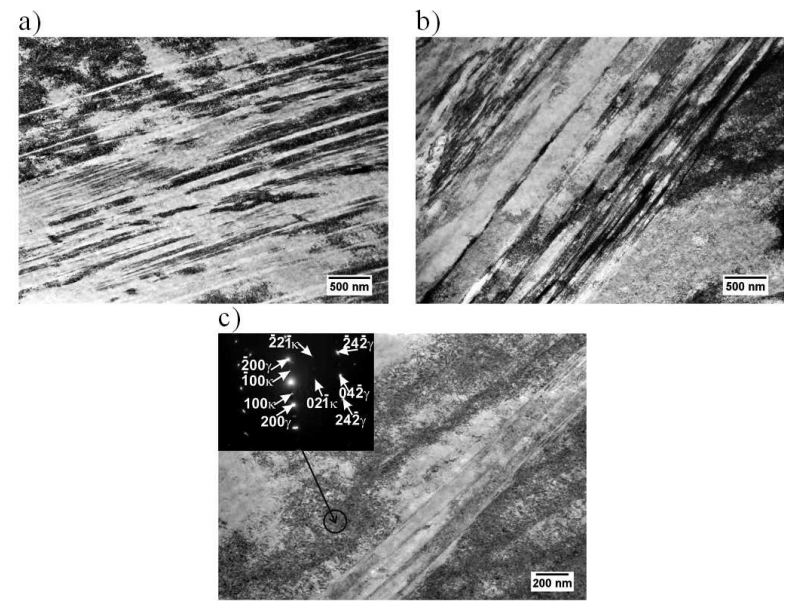

Fig. 3. TEM micrographs of X85MnAl29-9 steel after $50 \%$ cold rolling (a) and ageing at $550^{\circ} \mathrm{C}$ for $10 \mathrm{~h}$, bright field $(\mathrm{BF})$ and diffraction pattern $[012] \gamma \|[012] \kappa^{\prime}(\mathrm{b}, \mathrm{c})$.

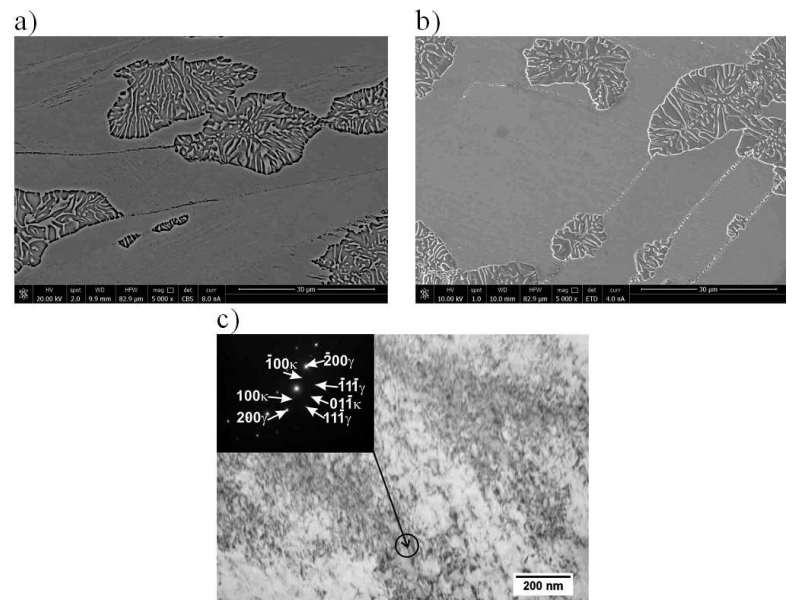

Fig. 4. Microstructures of $\mathrm{X} 85 \mathrm{MnAl} 29-9$ steel after $50 \%$ cold rolling and ageing at $550^{\circ} \mathrm{C}$ for $100 \mathrm{~h}$ : SEM micrographs (a)-(b), BF and diffraction pattern $[011] \gamma \|[011] \kappa^{\prime}(\mathrm{c})$.

In Figures 3 and 4, the microstructures of a highmanganese steel after deformation and annealing in different conditions are presented. There are numerous microtwins in the structure of the steel after reduction of $50 \%$ (Fig. 3a). After ageing at $550{ }^{\circ} \mathrm{C}$ for $10 \mathrm{~h}$, the effects of deformation are still visible in the austenite grains. High density of dislocations, microtwins and $\kappa^{\prime}$ carbides were observed (Fig. 3b,c). Extending the ageing time to $100 \mathrm{~h}$ results in the precipitation of $\kappa$ carbide on the boundaries of the grains of austenite and twins as a result of the following reaction: $\gamma \rightarrow \gamma_{0}$ (carbon-depleted austenite) $+\kappa$ (Fig. 4a,b). There is also precipitation of $\kappa^{\prime}$ within the austenite matrix by spinodal decomposition (Fig. 4c). That process is intensified when ageing is extended. The precipitation of $\kappa$ carbide in austenite is both confirmed by the diffraction examinations, and indicated by the observations of microstructure.

\section{Summary}

X-ray diffraction examinations and observations of microstructure confirm that in the course of the ageing of a high-manganese steel, precipitation of $\kappa$ and $\kappa^{\prime}$ carbides occurs. $\kappa$ carbide is formed on the boundaries of the grains of austenite, whereas $\kappa^{\prime}$ carbide in the austenitic matrix. The appearance of satellites next to the basic lines on the X-ray examination records indicates that carbides $\kappa^{\prime}(\mathrm{Fe}, \mathrm{Mn})_{3} \mathrm{AlC}$ are formed in the austenitic matrix as the result of spinodal decomposition. Carbide phase formation processes clearly influence the development of texture of austenite. The texture of austenite is principally described by the main components belonging to the fibre $\alpha$.

\section{Acknowledgments}

The work supported by the Polish Committee for Scientific Research under the contract 11.11.110.299. Appreciation is also expressed to Prof. A.S. Wronski (University of Bradford, UK), who edited the text.

\section{References}

[1] J. Kowalska, W. Ratuszek, M. Witkowska, A. Zielińska-Lipiec, Solid State Phenom. 203204, 115 (2013).

[2] C.S. Wang, C.N. Hwang, C.G. Chao, T.F. Liu, Scr. Mater. 57, 809 (2007).

[3] C.L. Lin, C.G. Chao, H.Y. Bor, T.F. Liu, Mater. Trans. 51, 1084 (2010).

[4] K.H. Han, Mater. Sci. Eng. A 197, 223 (1995).

[5] M. Witkowska, A. Zielińska-Lipiec, J. Kowalska, W. Ratuszek, Arch. Metall. Mater. 59, 971 (2014).

[6] C.Y. Chao, T.F. Liu, Metall. Trans. A 24, 1957 (1993).

[7] G. Tsay, Y. Tuan, C. Lin, C. Chao, T. Liu, Mater. Trans. 52, 521 (2011).

[8] C.Y. Chao, C.N. Hwang, T.F. Liu, Scr. Mater. 28, 109 (1993).

[9] J. Kowalska, W. Ratuszek, M. Witkowska, A. Zielińska-Lipiec, J. Alloys Comp. 615, 583 (2014). 